\title{
A study of variation in soil gas concentration associated with earthquakes near Indo-Burma Subduction zone
}

\author{
Sanjay Singh ${ }^{1}$, Hari Prasad Jaishi ${ }^{1}$, Raghavendra Prasad Tiwari $^{2}$ and Ramesh Chandra Tiwari ${ }^{{ }^{*}}$
}

\begin{abstract}
Background: In the recent past, several efforts have been made by a number of researchers to measure anomalous emanations of geo-gases in seismic prone regions of the world and radon has been the most preferred geo-gas as possible earthquake precursor since it is easily detectable.

Results: In the present investigation, continuous measurements of radon concentration at $80 \mathrm{~cm}$ inside the soil has been carried out at Chite Fault $\left(23.73^{\circ} \mathrm{N}, 92.73^{\circ} \mathrm{E}\right)$, Aizawl, Mizoram situated in the seismic zone V in North Eastern part of India near Indo-Burma subduction zone, using LR-115 Type-II nuclear track detectors manufactured by Kodak Pathe, France. During the investigation period, the radon concentration varied from $163.27 \mathrm{~Bq} / \mathrm{m}^{3}$ to $2557.82 \mathrm{~Bq} / \mathrm{m}^{3}$ with an average and standard deviation of $1116.15 \mathrm{~Bq} / \mathrm{m}^{3}$ and $591.76 \mathrm{~Bq} / \mathrm{m}^{3}$ respectively.

Conclusion: Certain anomalies observed in radon concentration have been correlated to the earthquakes within the range of magnitudes $4.7 \leq M \leq 5.5$, while some other anomalies are due to the influence of meteorological parameters.
\end{abstract}

Keywords: Soil-gas, Radon, LR-115 films, Correlations, Meteorological parameters, Earthquake

\section{Background}

Migration of carrier gas by bubbles is considered to be an important transport mechanism governing distribution of carrier $\left(\mathrm{CO}_{2}\right.$ and $\left.\mathrm{CH}_{4}\right)$ and trace $(\mathrm{Rn}, \mathrm{He})$ gases over wide areas on the earth surface. Soil-gas anomalies and chemical changes in groundwater, observed during seismic events may be attributed to gas carrier dynamics (Etiope and Martinelli, 2002). During the last several decades, analysis of earthquake precursory phenomena reveals that significant changes in geophysical and geochemical process may occur prior to intermediate and large earthquake. The behavior of the gas concentration anomalies has been quite variable. Several investigators have reported increase in gas concentrations before the occurrence of seismic events (Cai et al., 1984; Nersesov, 1984; Kawabe, 1985). Besides these, declines in radon concentration or concentration ratio immediately and prior to seismic events have also been reported (King et al., 1981;

\footnotetext{
* Correspondence: ramesh_mzu@rediffmail.com

${ }^{1}$ Department of Physics, Mizoram University, Aizawl 796004, India Full list of author information is available at the end of the article
}

Barsukov et al., 1985; Sugisaki and Sugiura, 1986). In some cases, anomalies have also occurred contemporaneously with or after the events (Birchard and Libby, 1980; King, 1985; Thomas et al., 1986). Soil-gas concentrations are not sensitive to hydrologic changes as they are extremely susceptible to a number of other environmental effects. However, many authors in the past suggest that spatial and temporal variations in soil-gas concentrations are most intensively influenced by meteorological interferences (Kraner et al., 1964; Klusman, 1981; Fleischer, 1983; Robinson and Whitehead, 1986; Guedalia et al., 1970).

\section{Radon emanation and earthquake}

Radon concentration in the soil-gas increases with depth (Jonsson, 1995; Kristiansson and Malmqvist, 1984) until a certain depth is reached which depend on the soil's properties and moisture content. Radon act as an indicator for changes in the gas streams. The most sensitive depth to detect such changes is between 0.5 to $1 \mathrm{~m}$ (Friedmann, 2012). Since 1971 much effort has been devoted to explain earthquake on the basis of Dilatancy and fluid flow (Scholz et al., 1973). Dilatancy means an 


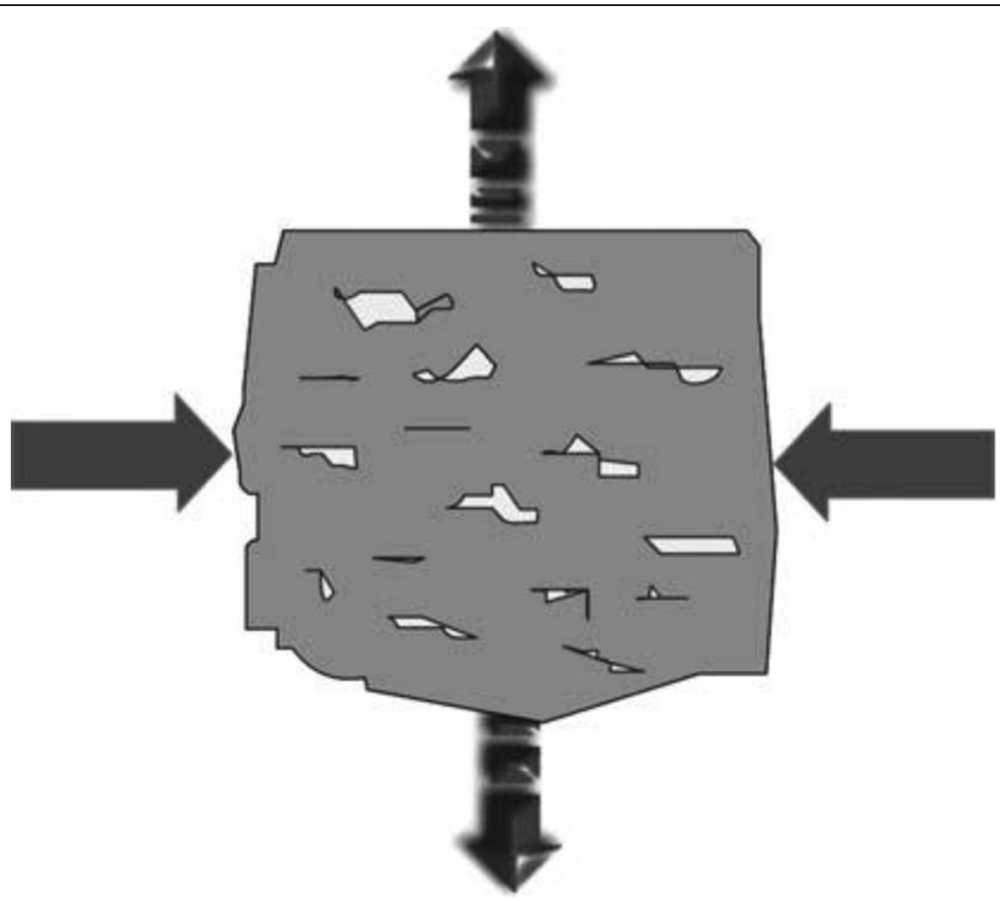

Fig. 1 Dilatancy: increasing stress causes cracks in the rock, which enlarges the material perpendicular to the main axis of stress. This causes an effective increase in volume (after Friedmann, 2012)

elastic increase in volume under stress as shown in Fig. 1. According to the Dilatancy theory, a substantial change (increase in the perpendicular direction to the main axis of the stress) in the rock properties will occur shortly before earthquake leading to the possibility of water penetration in the cracks and/or the number of cracks increases exponentially. As a result, significant masses are moved which will cause the movement of subsurface soil-gas towards the earth surface (Friedmann, 2012). Consequently opening of new cracks, widening or closing of old cracks or redistribution of open and closed cracks can happen. In dry rocks opening or closing of cracks will lead to significant changes of the diffusion coefficient of radon. Volumetric changes in the rock will also lead to a subsurface gas flow and therefore to an additional radon transport. If the new open cracks are filled with water, the increased water-rock interface leads to an increase in the transfer of radon from the rock matrix to the water. If water filled cracks close, the water will be compressed to another subsurface volume where the emanation from the rock to the water may be different. All these effects result in pressure and water level variations of the relevant aquifer. This may also lead to changes in the mixing ratios for the water which can be observed at the earth's surface. Finally gas flows can also move some groundwater and again all previously discussed mechanisms which are consequences of the redistribution of water in the earth's crust can take into effect (Imme and Morelli, 2012).

\section{Seismicity of the study area}

Earthquake most probably occurs due to movements along the faults that have evolved through geological and tectonic processes. Northeast India is considered one of the six most seismically active regions of the world. The Tectonic Map of Northeast India is shown in Fig. 2. The region has experienced 18 large earthquakes $(M \geq 7)$ during the last hundred years and several hundred small or micro earthquakes. The high seismicity in the region is attributed to the collision tectonics between the Indian plate and Eurasian plate in the north and subduction tectonics along the Indo-Myanmar range in the east (Kayal, 1998; Sarmah, 1999). There has been a phenomenal increase in the population density and development programmes in the northeast India. Besides, the region has witnessed a mushroom growth of unplanned urban centers in the previous two decades. This has resulted into increasing vulnerability of human population and physical structures to the earthquakes. Thus, it becomes essential to assess the status of seismicity in the northeastern region realistically. This will provide a sound database for earthquake disaster mitigation. Moreover, high seismic risk in the region calls for an 


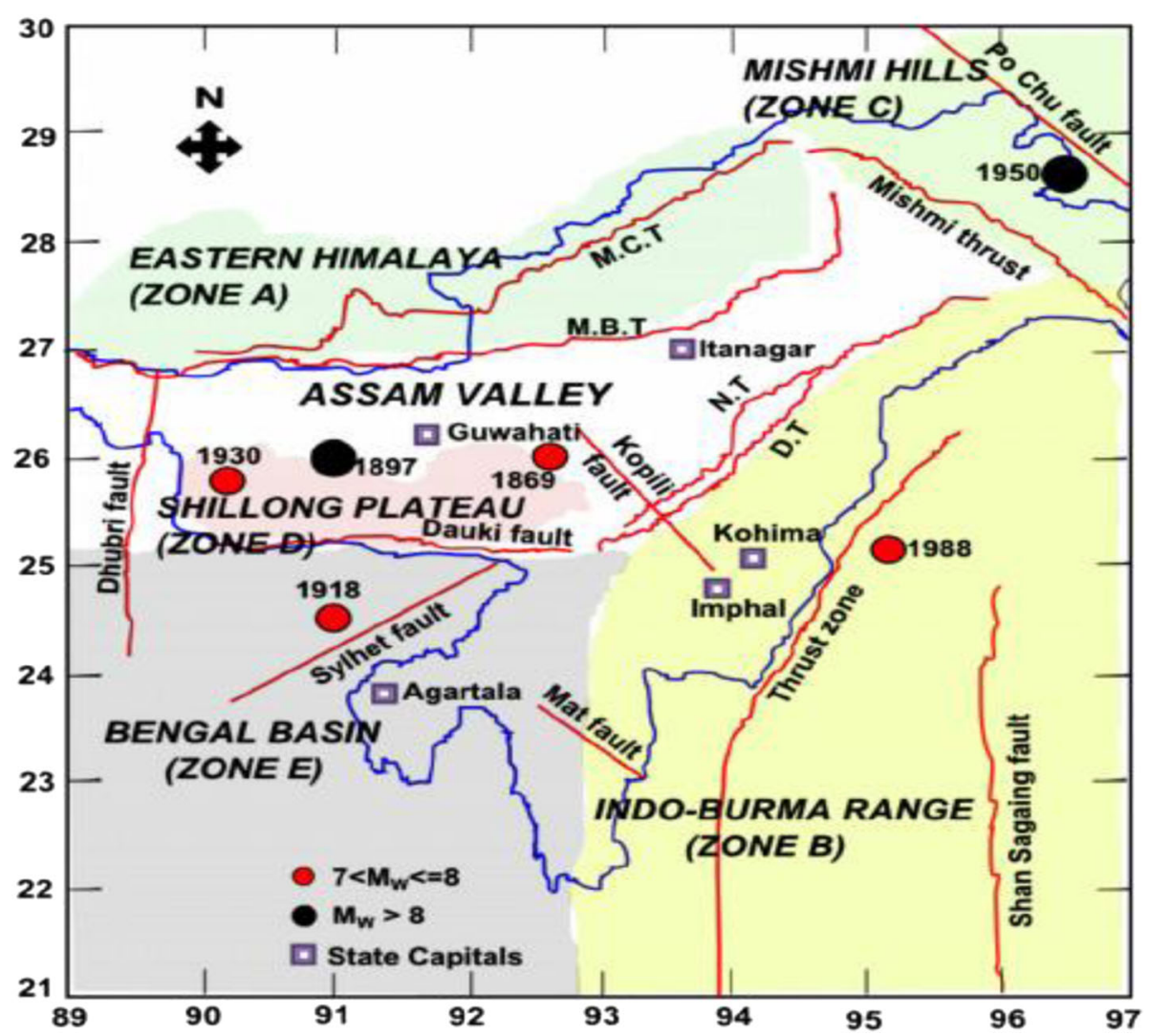

Fig. 2 Seismo-tectonic map of North East India showing epi-centres of damaging earthquakes (after Jaishi et al., 2014c). Tectonic zones (zones A, B, C, D and E) and major thrusts (MBT-Main Boundary Thrust; MCT-Main Central Thrust; NT-Naga Thrust; DT-Disang Thrust) are also shown. Thick blue line represents the International boundary of North Eastern part of India bordering Myanmar and Bangladesh (not to scale) and red lines represents faults and thrusts

urgent and sustained mitigation effort. Accordingly, there seems to be a real need for employing all available efforts including radon variations and seismicity records that may assist in reducing seismic risk in the area. Radon variations might seem to be a good precursor of crustal motion resulting in earthquakes. This fact encourages researchers to find a way of using this phenomenon for earthquakes prediction. However earthquakes are not always preceded by a radon anomaly and not every radon increase is followed by an earthquake. But the radon technique has been successfully used in several seismic areas of the world for the purpose of earthquake precursory research. Based on the status of seismicity in the northeastern India, it seems very necessary to apply whatever available techniques which may help to understand the behavior of soil-gas radon concentration and correlate with nearby seismic events. Keeping the above in view, present authors began studies of radon variation as a possible seismic precursor in 2011 at Mat Fault in Mizoram for the first time and the results of this work have been reported (Jaishi et al., 2013; 2014a; 2014b;). Encouraged with the outcome and for future research, authors extended radon measurement at weekly interval at Chite Fault (Singh et al., 2014). The location of the study area is shown in Fig. 3. The main objective of this study is continuous monitoring of soil radon and their possible correlation with seismic events. The present paper reports continuous soil radon measurements carried out at Chite Fault from August 2013 to January 2014.

\section{Experimental techniques and methods}

Solid State Nuclear Track Detector (SSNTD) is one of the most widely used devices for the last few decades for measuring radon concentration in earthquake precursory studies. In the present investigation, weekly measurements were carried out using LR-115 Type-II SSNTD films manufactured by M/S Kodak Pathe, France. The detectors (LR-115 Films) were cut into a size of $3 \mathrm{~cm} \times 3 \mathrm{~cm}$ and loaded in a twin cup radon/thoron discriminating dosimeters, designed and fabricated by Mayya and group (Mayya et al., 1998) at BARC, Mumbai (India). The experimental detail is discussed in Singh et al. (2014). The meteorological parameters for the study area were obtained from the IMD-Regional Meteorological Centre, Guwahati, 


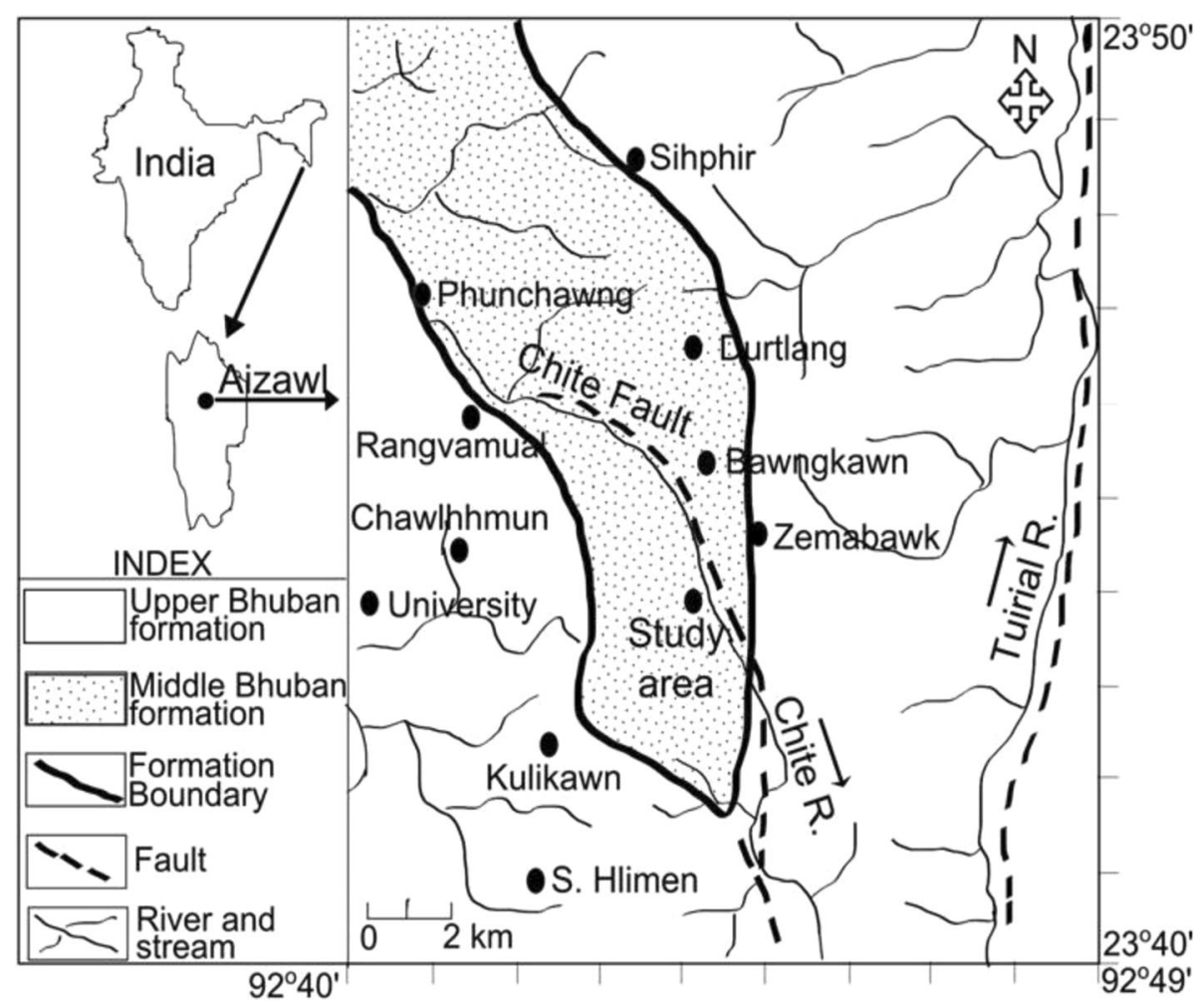

Fig. 3 Geographical location of the study area

Assam. Due to certain constraints integrated measurement for 7 days was taken for the soil gas instead of daily recording. Total rainfall was calculated for 7 days. Temperature, pressure and relative humidity are the moving average of 7 days. Regarding selection of seismic activity that could correlated with radon data there is no such general rule with respect to epicenter distance from the measuring sites. Virk (1996) modified the model proposed by Fleischer (1981) by considering 142 case studies in N-W Himalaya, India as

$$
\left.D=\begin{array}{l}
10 \exp (0.32 M),(10<D<50) \\
10 \exp (0.43 M),(50<D<100) \\
10 \exp (0.56 M),(100<D<500) \\
10 \exp (0.63 M),(500<D<1250)
\end{array}\right\}
$$

Where, $D$ is the epicenter distance in $\mathrm{km}$ and $M$ is the magnitude of earthquake on the Richter scale. The details of earthquakes that occurred around the study area fulfilling Eq. (1) is given in Table 1 and the distribution of the earthquakes that occurred around the study area is presented in Fig. 4.

\section{Results and Discussions}

Normality test

Before correlating the measured radon data set with meteorological parameters, we wanted to check whether the radon data shows normal distribution, which is inevitable because the soil radon data obeying the fundamental laws of geochemistry are usually normally distributed (Ahrens, 1954). To do this we performed normality test which is used to determine whether a data set resembles the normal distribution. In the present work, authors have implemented normal probability plot to perform normality test in Microsoft excel, 2007. One characteristic that defines the normal distribution is that normally distributed data will

Table 1 Lists of earthquakes that occurred around the investigation area during the observation period (source: www.imd.gov.in)

\begin{tabular}{llllllll}
\hline Date of event & $\begin{array}{l}\text { Date of anomaly } \\
\text { observed }\end{array}$ & Latitude $\left({ }^{\circ} \mathrm{N}\right)$ & Longitude $\left({ }^{\circ} \mathrm{E}\right)$ & Depth (km) & Magnitude & Epicenter distance (km) & $\begin{array}{l}\text { Precursor/postcursor } \\
\text { time (Days) }\end{array}$ \\
\hline $09 / 07 / 2013$ & $09 / 06 / 2013$ & $25.3^{\circ} \mathrm{N}$ & $94.9^{\circ} \mathrm{E}$ & 90 & 4.8 & 278 & 1 \\
$10 / 29 / 2013$ & $10 / 25 / 2013$ & $22.9^{\circ} \mathrm{N}$ & $94.2^{\circ} \mathrm{E}$ & 46 & 4.7 & 176 & 4 \\
$11 / 06 / 2013$ & $10 / 25 / 2013$ & $26.5^{\circ} \mathrm{N}$ & $93.5^{\circ} \mathrm{E}$ & 20 & 5.5 & 320 & 12 \\
$12 / 30 / 2013$ & $12 / 06 / 2013$ & $24.3^{\circ} \mathrm{N}$ & $93.2^{\circ} \mathrm{E}$ & 10 & 4.5 & 78 & 24 \\
\hline
\end{tabular}




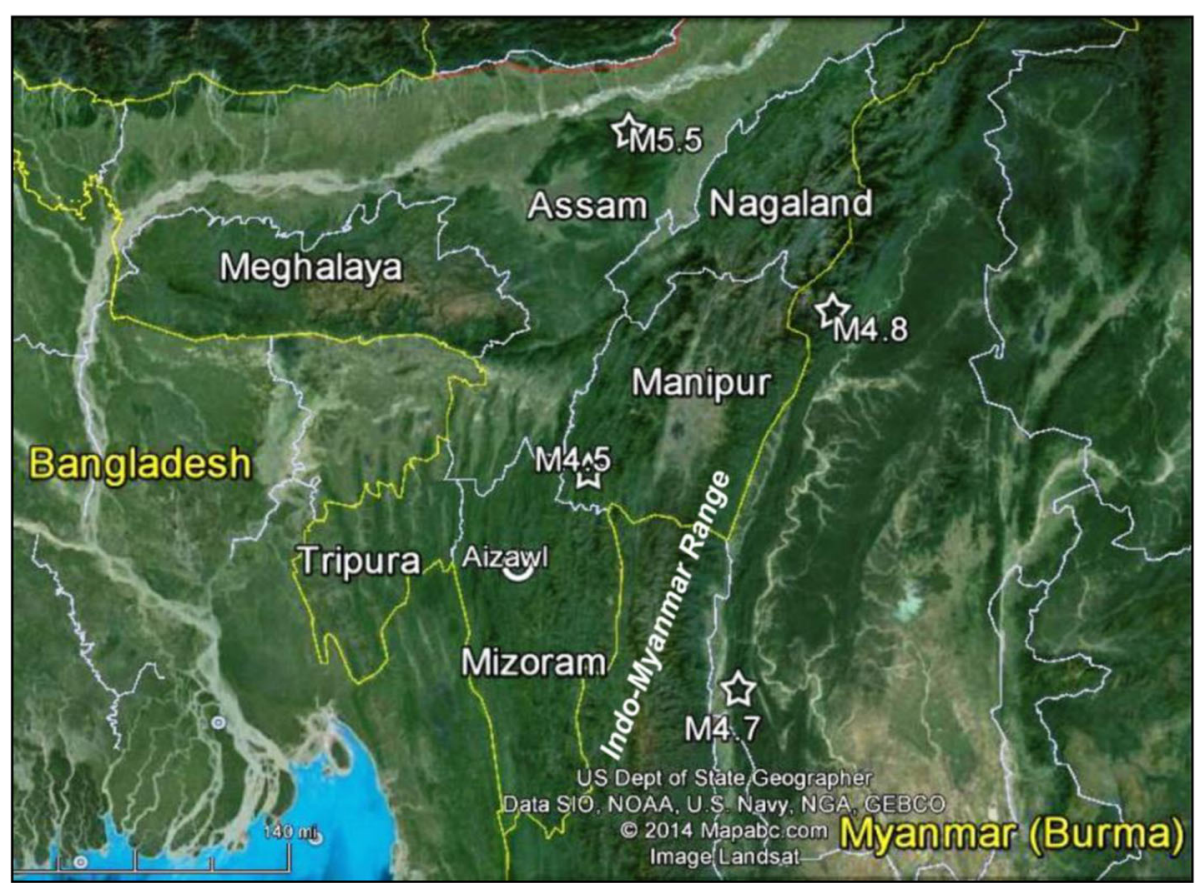

Fig. 4 Spatial distribution of earthquakes (open star) around the study area during the investigation period

have the same amount of area of normal curve between each point. The area under the normal curve between each point can be determined by cumulative distribution function $(\mathrm{CDF})$ using the following Excel formula.

$\mathrm{CDF}=$ NORMDIST (Radon value, mean, standard deviation, TRUE)

Now the CDF value of each Radon value is used for calculating the expected radon values and Z- score at each radon value by the following formulae.
NORMSINV (CDF at each radon value) for Z-score, and NORMINV (CDF at each radon value, mean, standard deviation) for expected values.

A plot of expected radon values versus Z-score will be a straight line. We now observed the actual radon data compared to the expected radon data for normally distributed data having the same mean and standard deviation and observed that the actual radon data maps closely to the expected radon values (Fig. 5). So it may be concluded that the data is derived from a normally distributed

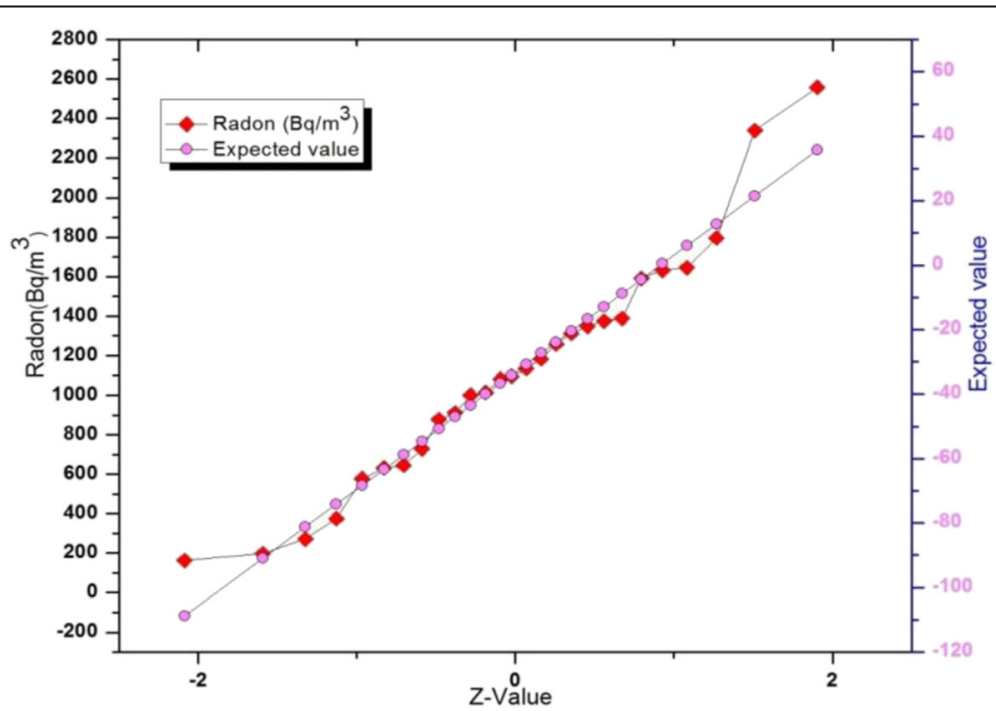

Fig. 5 Normal probability plot comparing actual radon value with expected radon value 
population. Also, the skew factor of the radon data was calculated and it was found to be 0.49 indicating that the radon value is slightly skewed towards the right. In order to check the significance of skew factor we have used the Excel formula viz. if skew $>2$ sqrt(6/count) then the skew factor is significant (i.e. the distribution is not normal) and if skew $<2$ *sqrt(6/count) then it is non-significant (i.e. the distribution is normal). In our case the skew factor was found to be non- significant (i.e., $0.49<0.94$ ).

\section{Effects of meteorological parameters on radon concentration}

Analysis of radon concentration in soil gas along with meteorological parameters viz. temperature, rainfall, relative humidity and pressure provide useful information about the dependence of these parameters on radon emanation. The average concentration of radon in soil gas at Chite fault for this time window is reported to be $1116.15 \mathrm{~Bq} / \mathrm{m}^{3}$ with a standard deviation of $591.76 \mathrm{~Bq} / \mathrm{m}^{3}$. The percentage variation co-efficient $(\sigma / \mathrm{Avg}$.) of radon is $53.02 \%$ (Table 2). From Table 2 it is clear that the measured radon shows a very low positive correlation with temperature and rainfall i.e. the value of radon concentration increases with increase in these parameters and vice versa. The reason may be due to the capping effect of wet soil layers at the surface which prevents radon from escaping in to the atmosphere (Virk et al., 2000). As a result the radon values initially falls and then start rising over a period of time. A moderate positive correlation coefficient of 0.31 was found between radon and relative humidity. The percentage variation coefficient was found to be $6.96 \%$. This demonstrates that the variation in radon emission was much more influenced by relative humidity rather than temperature and rainfall. Therefore, increase in soil moisture may increase the fraction of radon produced in rocks to migrate into pore fluids, thus increasing the radon content of soil gas (Tanner, 1964; Fleischer, 1983). A very low negative correlation coefficient $(-0.005)$ was found between radon and pressure suggesting that pressure have a non-significant influence on the measured radon concentration during the investigation period.

\section{Correlation of radon concentration with seismic events}

Various statistical methods have been used by different authors in the past (Guerra and Lombardi, 2001; Fu et al., 2005; Yang et al., 2005; Walia et al., 2005) for identifying possible threshold values of the anomalous radon concentrations. A very common approach could be to examine the difference between radon peak and the mean value of the radon concentration for a few months or a year. In our case, the average value of radon concentration $(\mathrm{X})$ is taken as the background level and the value crossing $X \pm 2 \sigma$ (mean \pm 2 standard deviation) is considered as anomalous. In cases when the radon maximum increases or decreases by $\pm 1 \sigma$ from its mean, a possible influence of the meteorological parameters is carefully examined and accordingly a radon anomaly is assumed. The variation of radon concentration together with the meteorological parameters for the given time period is presented in Fig. 6.

According to the characteristics trends of radon concentration as illustrated in Fig. 6, there are three positive peaks and three negative peaks recorded during the given time period. The first radon peak (negative anomaly) was observed on 9/6/2013 followed by an event of 4.8 $\mathrm{M}$ which occurred on $9 / 7 / 2013$. Since the observed peak do not crosses the $\mathrm{X}-2 \sigma$ limit, therefore it seems necessary to investigate the behavior of meteorological parameters carefully. During this period the relative humidity and rainnfall, which shows positive correlation with radon was quite low. Therefore, this decline in radon concentration is attributed and/or have caused by variation in meteorological parameters and not by seismic events. The second radon peak (negative) was recorded on 4/10/2013. During this time period a fair amount of rainfall was received and the temperature and humidity which shows positive correlation with radon were quite high indicating that this decline in radon concentration is caused by some other geophysical process which was not mature enough to produce an earthquake (Walia et al., 2009). Three consecutive positive radon peaks were recorded on 10/11/2013 and 10/ $25 / 2013$ crossing the $X+2 \sigma$ limit while the third peak on $11 / 8 / 2013$ just exceeding $X+1 \sigma$ level followed by two seismic events of $4.7 \mathrm{M}$ and $5.5 \mathrm{M}$ recorded on 10/ $29 / 2013$ and 11/6/2013 with an epicenter distances of $176 \mathrm{~km}$ and $320 \mathrm{~km}$ from the measuring site. These positive anomalies may be due to the combining effects of these two earthquakes. The positive radon anomalies can be explained by the Dilatancy-diffusion model

Table 2 Descriptive statistics of radon and the meteorological parameters

\begin{tabular}{lllll}
\hline Parameter & Average (Avg.) & Standard deviation $(\sigma)$ & \% Variation coefficient $(\sigma /$ Avg.) & Correlation coefficient \\
\hline Radon $\left(\mathrm{Bq} / \mathrm{m}^{3}\right)$ & 1116.15 & 591.76 & 53.02 & - \\
Temperature $\left({ }^{\circ} \mathrm{C}\right)$ & 22.24 & 3.83 & 17.2 & 0.16 \\
Rainfall $(\mathrm{mm})$ & 40.03 & 51.92 & 129.7 & 0.16 \\
Humidity $(\%)$ & 81.80 & 5.63 & 6.88 & 0.31 \\
Pressure $(\mathrm{mbar})$ & 960.81 & 5.59 & 0.58 & -0.01 \\
\hline
\end{tabular}




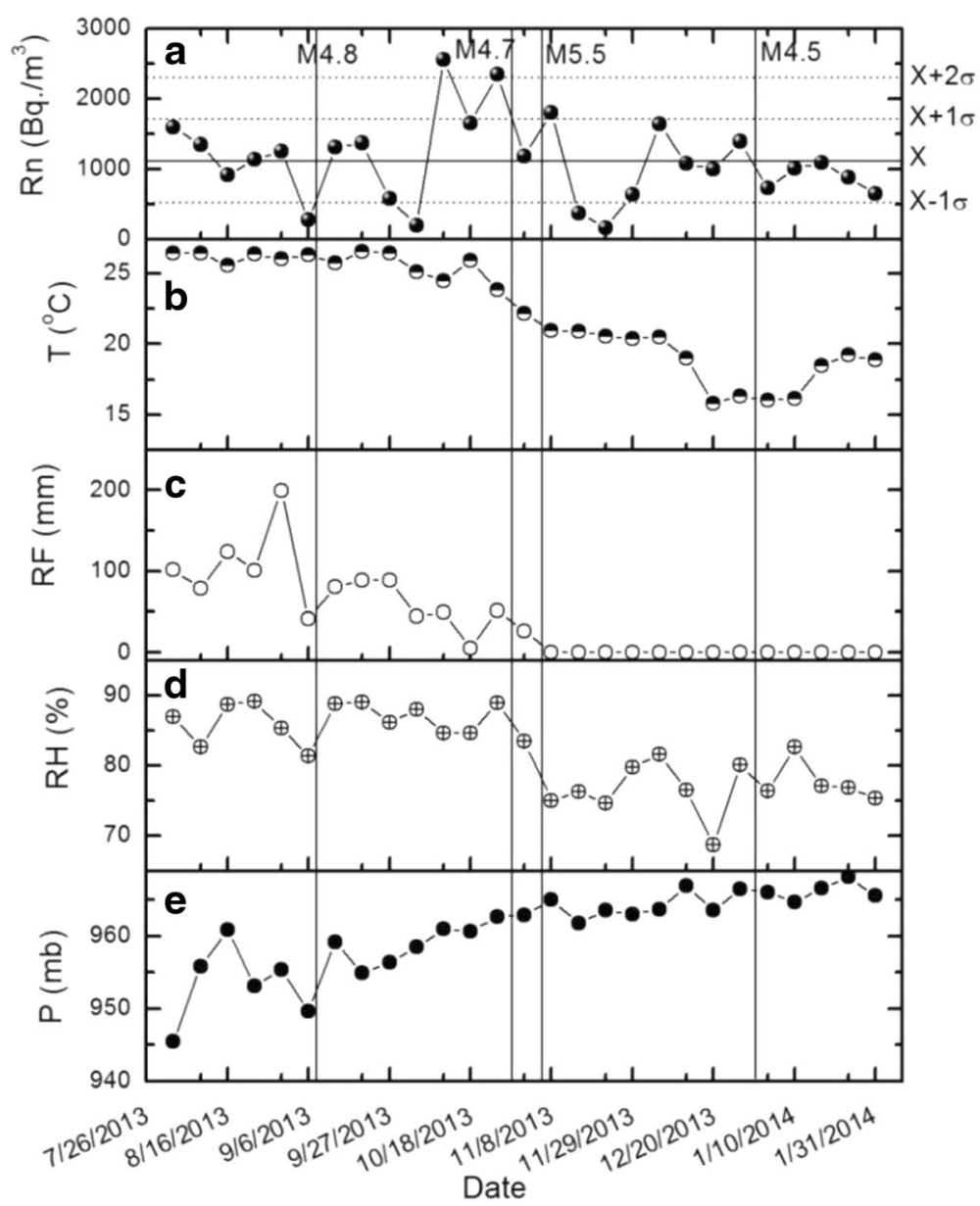

Fig. 6 Plot showing the variation of a Radon concentration $R n$, $\mathbf{b}$ Temperature $T$, c Relative humidity $R H$, d Rainfall $R F$, e Pressure $P$ during the observation period. The vertical lines represent earthquakes along with their magnitude. The solid horizontal line represents the average value of radon concentration $(X)$ and the dotted lines represent the deviation $(\sigma)$ from the average value

(Mjachkin et al., 1975) where the increase in radon content prior to earthquakes is connected with the amount of cracking of rocks and therefore is sharply increased and then flattens out due to relaxation of stress. Another sharp fall in radon concentration was observed on 11/ $22 / 2013$ but no seismic events occurred during this period. Besides, it is quite difficult to explain such a large radon decrease by environmental parameters. This abrupt decrease in radon concentration may be either due to additional compression closing cracks and pores (Singh et al., 1991; Ramola et al., 2008) or from expansion causing under saturation of the pore volume (Whitcomb, 1983).

\section{Conclusion}

In the present study, the radon data generated during the mentioned time period have been analyzed with seismic events and meteorological parameters. Some considerable positive radon anomalies have been observed crossing the limits of $X+2 \sigma$ before and after the earthquake of 4.7 and 5.5 magnitude. Such variation in radon concentration could be due to crustal deformation along Indo-Myanmar subduction zone during these two seismic events. Besides these, few abnormal declines in radon data having negative correlation with seismicity were also recorded. It can be concluded that these changes may be either because of meteorological parameters influencing radon concentration or due to the complexity of its transport mechanism from deeper soil. However, for better correlation and to pinpoint the seismic event with anomaly, longer periods of data collection along with measurements of other carrier and trace gases (like thoron).

\section{Acknowledgements}

This work was funded by the Ministry of Earth Sciences (MoES), Govt. of India, New Delhi; in the form of Major project vide Sanction Order No. MoES/ P.O.(Seismo)/1(167)/2013 Dated 10.12.2013.

\section{Author's contributions}

SS collected the data and drafted the manuscript. HPJ helped to collect the data and performed the statistical analysis. RPT helped to draft the manuscript 
and site selection. RCT helped in the experimental design, participated in the extensive revision and overall supervision. All authors read and approved the final manuscript.

\section{Competing interests}

The authors declare that they have no competing interests.

\section{Author details}

'Department of Physics, Mizoram University, Aizawl 796004, India.

2Department of Geology, Mizoram University, Aizawl 796004, India.

Received: 25 May 2016 Accepted: 11 November 2016

Published online: 22 November 2016

\section{References}

Ahrens, L.H. 1954. The lognormal distribution of the elements (a fundamental law of geochemistry and its subsidiary). Geochimica et Cosmochimica Acta 5: 49-73.

Barsukov, V.L., G.M. Varshal, and N.S. Zamokina. 1985. Recent results of hydrogeochemical studies for earthquake prediction in the USSR. Pure and Applied Geophysics 122: 143-156.

Birchard, G.F., and W.F. Libby. 1980. Soil radon concentration changes preceding and following four magnitude 4.2-4.7 earthquakes on the San Jacinto Fault in southern California. Journal of Geophysical Research 85: 3100-3106.

Cai Z, Shi H, Zhang W, Luo GEX, Shi X, Yang H. 1984. Some applications of fluidgeochemical methods to earthquake prediction in China: International symposium on continental seismology and earthquake prediction, 384-395. Beijing (China): Seismological Press.

Etiope, G., and G. Martinelli. 2002. Migration of carrier and trace gases in the geosphere: an overview. Physics of the Earth and Planetary Interiors 129(3): 185-204

Fleischer, R.L. 1981. Dislocation Model for radon response to distant earthquakes. Geophysical Research Letters 8(5): 477-480.

Fleischer, R.L. 1983. Theory of alpha recoil effects on radon release and isotopic disequilibrium. Geochimica et Cosmochimica Acta 47(4): 779-784

Friedmann, H. 2012. Radon in earthquake prediction research. Radiation Protection Dosimetry 149: 177-184.

Fu, C.C., T.F. Yang, V. Walia, and C.H. Cheng. 2005. Reconnaissance of soil gas composition over the buried fault and fracture zone in southern Taiwan. Geochemical Journal 39(5): 427-439.

Guedalia, D., J.L. Laurent, J. Fontan, D. Blanc, and A. Druilhet. 1970. A study of radon 220 emanation from soils. Journal of Geophysical Research 75(2): 357-369.

Guerra, M., and S. Lombardi. 2001. Soil-gas method for tracing neotectonic faults in clay basin: the Pisticci field (southern Italy). Tectonophysics 339(3): 511-522.

Imme G, Morelli D. 2012. Radon as earthquake precursor. In: Earthquake Research and Analysis-Statistical Studies, Observation and Planning (Dr. Amico S.D., Ed.), ISBN: 978-953-51-0134-5, In Tech, Available from: http://www.intechopen.com/ books/earthquake-research-and-analysis-statistical-studies-observations-andplanning/radon-as-earthquake-precursor.

Jaishi, H.P., S. Singh, R.P. Tiwari, and R.C. Tiwari. 2013. Radon and thoron anomalies along Mat fault in Mizoram, India. Journal of Earth System Science 122(6): 1507-1513.

Jaishi HP, Singh S, Tiwari RP, and Tiwari RC (2014a) Correlation of radon anomalies with seismic events along Mat fault in Serchhip District, Mizoram, India. Applied Radiation and Isotopes 86:79-84.

Jaishi HP, Singh S, Tiwari RP, and Tiwari RC (2014b) Temporal variation of soil radon and thoron concentrations in Mizoram (India), associated with earthquakes. Natural Hazards 72(2):443-454.

Jaishi HP, Singh S, Tiwari RP, and Tiwari RC (2014c) Analysis of soil radon data in earthquake precursory studies. Annals of Geophysics 57(5): S0544; doi:10. 4401/ag-6513.

Jonsson, G. 1995. Radon gas- where from and what to do? Radiaiation Measurements 25: 1-4

Kawabe, I. 1985. Anomalous changes of $\mathrm{CH}_{4} / \mathrm{Ar}$ ratio in subsurface gas bubbles as seismogeochemical precursors at Matsuyama, Japan. Pure and Applied Geophysics 122(2-4): 196-214

Kayal, J.R. 1998. Seismicity of Northeast India and surroundings: Development over the past 100 years. Journal of Geophysics 19(1): 9-34.

King, C.Y. 1985. Impulsive radon emanation on a creeping segment of the San Andreas Fault, California. Pure and Applied Geophysics 122(2-4): 340-352.
King, C.Y., W.C. Evans, T. Presser, and R.H. Husk. 1981. Anomalous chemical changes in well water and possible relation to earthquakes. Geophysical Research Letters 8(5): 425-428.

Klusman, R.W. 1981. Variations in mercury and radon emission at an aseismic site. Geophysical Research Letters 8(5): 461-464.

Kraner, H.W., G.L. Schroeder, and R.D. Evans. 1964. Measurement of the effects of atmospheric variables on radon-222 flux and soil-gas concentrations. Symposium Proceedings Natural Radiation Environment, Houston, Texas, 10-13 April 1963, 191-214. Chicago: University of Chicago Press.

Kristiansson K, Malmqvist L. 1984. The depth dependence of the concentration of sup Rn-222 in soil gas near the surface and its implication for exploration. Geoexploration 22:17-41.

Mayya, Y.S., K.P. Eappen, and K.S.V. Nambi. 1998. Methodology for mixed field inhalation dosimetry in monazite areas using a twin-cup dosimeter with three track detectors. Radiation Protection Dosimetry 77(3): 177-184.

Mjachkin, V.I., W.F. Brace, G.A. Sobolev, and J.H. Dieterich. 1975. Two models for earthquake forerunners. Pure and Applied Geophysics 113: 169-181.

Nersesov IL. 1984. Development of earthquake prediction in the USSR. International symposium on continental seismicity and earthquake prediction, 373-383. Beijing (China): Seismological Press.

Ramola, R.C., Y. Prasad, G. Prasad, S. Kumar, and V.M. Choubey. 2008. Soil-gas radon as seismotectonic indicator in Garhwal Himalaya. Applied Radiation and Isotopes 66(10): 1523-1530.

Robinson, R., and N.E. Whitehead. 1986. Radon variations in the Wellington region, New Zealand, and their relation to earthquakes. Earthquake Prediction Research 4: 69-82.

Sarmah, S.K. 1999. The probability of occurrence of a high magnitude earthquake in Northeast India. Journal of Geophysics 20(3): 129-135.

Scholz, C.H., L.R. Sykes, and Y.P. Aggarwal. 1973. Earthquake prediction: a physical basis. Science 181: 803-810.

Singh M, Ramola RC, Singh B, Singh S, Virk HS (1991) Subsurface soil gas radon changes associated with earthquakes. International Journal of Radiation Applications and Instrumentation. Part D. Nuclear Tracks and Radiation Measurements 19(1):417-420.

Singh, S., H.P. Jaishi, R.P. Tiwari, and R.C. Tiwari. 2014. Variations of soil radon concentrations along Chite Fault in Aizawl district, Mizoram, India. Radiation Protection Dosimetry. doi:10.1093/rpd/ncu221.

Sugisaki, R., and T. Sugiura. 1986. Gas anomalies at three mineral springs and a fumaroles before an inland earthquake, Central Japan. Journal of Geophysical Research 91(B12): 12296-12304.

Tanner, A.B. 1964. Radon migration in the ground: A review, Symposium Proceedings Natural Radiation Environment, 161-190. Chicago: University of Chicago Press.

Thomas, D.M., K.E. Cuff, and M.E. Cox. 1986. The association between ground gas radon variations and geologic activity in Hawaii. Journal of Geophysical Research 91(B12): 12186-12199.

Virk, H.S. 1996. A critique of empirical scaling relationship between earthquake magnitude, epicentral distance and precursor time for interpretation of radon data. Journal of Earthquake Prediction Research 5: 574-583.

Virk, H.S., V. Walia, A.K. Sharma, N. Kumar, and R. Kumar. 2000. Correlation of radon with microsiesmic events in Kangra and Chamba Valleys of N-W Himalaya. Geofisica Internacional 39(3): 222-227.

Walia, V., H.S. Virk, T.F. Yang, S. Mahajan, M. Walia, and B.S. Bajwa. 2005. Earthquake prediction studies using radon as a precursor in NW Himalayas, India: a case study. Terristrial Atmospheric and Oceanic Sciences 16(4): 775-804.

Walia, V., S.J. Lin, W.L. Hong, C.C. Fu, T.F. Yang, W.L. Wen, and C.H. Chen. 2009. Continuous temporal soil-gas composition variations for earthquake precursory studies along Hsincheng and Hsinhua faults in Taiwan. Radiation Measurements 44(9): 934-939.

Whitcomb JH. 1983. Modeling of tectonophysical distortion from measurements of long base-line geodetic data and other geophysical paramaters. NASA Grant No. NAG5-22 Semi-annual report, Colorado University. March-August 1980, 20p.

Yang, T.F., V. Walia, L.L. Chyi, C.C. Fu, C.H. Chen, T.K. Liu, S.R. Song, C.Y. Lee, and M. Lee. 2005. Variations of soil radon and thoron concentrations in a fault zone and prospective earthquakes in SW Taiwan. Radiation Measurements 40(2): 496-502. 